\title{
GÊNEROS EM CONTEXTO DIGITAL: UM PROTÓTIPO PARA O GÊNERO VIDEORRESENHA
}

\author{
Flávia Thaís Alves Britto (UFCG) \\ Williany Miranda da Silva (UFCG)
}

Resumo: A tradição sobre estudos de gêneros textuais destaca que o objeto reflete as multiformes e variadas esferas de utilização da linguagem. Em nossa sociedade, cada vez mais tecnológica, os ambientes digitais (re)criam os propósitos e as estruturas textuais para suprir as exigências das situações comunicativas diversas e dinâmicas. Assim, no contexto do YouTube, em tempos do fenômeno booktuber, o ato de resenhar modifica-se pela multimodalidade de vídeos e dos recursos específicos da rede social assumindo novos moldes, estratégias e funcionamento, possibilitando a origem do gênero videorresenha. $O$ presente artigo evidencia a videorresenha pretendendo responder ao questionamento: "Qual a estrutura prototípica para o gênero videorresenha está evidenciada em vídeos de canais do YouTube?". Para tanto, utilizamos uma metodologia descritivo-interpretativista e de inspiração netnográfica, objetivamos caracterizar a estrutura prototípica do gênero por meio da análise dos movimentos retóricos realizados em três videorresenhas disponíveis no suporte digital. Fundamentamo-nos inicialmente em Swales (1990), cujos métodos e teorias subsidiaram a criação de uma adaptação do modelo CARS que promoveu a constituição de um protótipo para o gênero em análise. Além deste, Bakhtin ([1979] 1997) e Miller (2012), dentre outros, nortearam a discussão em torno do tema, estrutura composicional e papéis sociais dos sujeitos que fomentam a existência dos gêneros em foco. Os resultados da pesquisa, em andamento, possibilitaram o reconhecimento de alguns movimentos retóricos similares ao consolidado gênero resenha, porém, a partir da inclusão de aspectos da multimodalidade, acrescenta-lhes outras características, possibilitando o reconhecimento de um novo gênero, influenciado pela dinâmica do ambiente digital.

Palavras-chaves: Ambiente digital; Videorresenha; YouTube.

ABSTRACT: The tradition about studies of textual genres emphasizes that the object reflects the multiform and varied spheres of language use. In our increasingly technological society, digital environments 
(re)create textual purposes and structures to meet the demands of diverse and dynamic communicative situations. Thus, in the context of YouTube, in times of the booktuber phenomenon, the act of reviewing is modified by the multimodality of videos and the specific resources of the social network assuming new molds, strategies and functioning, making possible the origin of the genre video review. This article highlights the video review intending to answer the question: "What prototypical structure for the genre video review is evidenced in videos of YouTube channels?". To do so, we use a descriptive-interpretative methodology and netnographic inspiration, aiming to characterize the prototypical structure of the genre by means of the analysis of the rhetorical movements realized in three video review available in the digital support. We base ourselves initially on Swales (1990), whose methods and theories subsidized the creation of an adaptation of the CARS model that promoted the constitution of a prototype for the genre under analysis. Besides this, Bakhtin ([1979] 1997) and Miller (2012), among others, guided the discussion around the theme, compositional structure and social roles of the subjects that foment the existence of the genres in focus. The results of the research, in progress, allowed the recognition of some rhetorical movements similar to the consolidated genre review, but, from the inclusion of aspects of multimodality, it adds to them other characteristics, allowing the recognition of a new genre, influenced by the dynamics of the digital environment.

Keywords: Digital environment; Video Review; YouTube.

\section{INTRODUÇÃO}

A tradição sobre estudos de gêneros textuais destaca que o objeto reflete as multiformes e variadas esferas de utilização da linguagem. Em nossa sociedade, cada vez mais tecnológica, os ambientes digitais (re)criam os propósitos e as estruturas textuais para suprir as exigências das situações comunicativas diversas e dinâmicas. 
Assim, no contexto do YouTube, em tempos do fenômeno booktuber ${ }^{1}$, o ato de resenhar modifica-se pela multimodalidade de vídeos e dos recursos específicos da rede social assumindo novos moldes, estratégias e funcionamento, possibilitando a origem do gênero videorresenha. O gênero híbrido, portanto, apresenta uma estrutura composicional particular que, apesar de semelhanças com formas textuais já consagradas, permite novos propósitos comunicativos e estilo.

Dessa forma, o presente artigo $^{2}$ evidencia a videorresenha pretendendo responder ao seguinte questionamento: "Qual a estrutura prototípica para o gênero videorresenha está evidenciada em vídeos de canais do YouTube?". Para tanto, objetivamos caracterizar a estrutura prototípica do gênero por meio da análise dos movimentos retóricos realizados em três videorresenhas disponíveis no suporte digital.

Fundamentamo-nos inicialmente em Swales (1990), cujo modelo CARS inspirou a constituição de um protótipo para

1 Muitos produtores de vídeos no YouTube se arvoram do direito de comentar a respeito de obras literárias e se apropriam da nomenclatura devido à grande popularidade que o termo booktuber tem alcançado, porém, atualmente, poucos realmente se afirmam como tal tendo em vista a emergente profissionalização que recebe tal denominação.

2 Este artigo se trata de um recorte da pesquisa de mestrado em andamento, vinculada ao projeto de pesquisa intitulado "Configurações de ensino em práticas multidisciplinares de linguagem (ns)", com duração prevista de 2018 a 2022 e, coordenado pelos professores doutores Edmilson Luiz Rafael e Williany Miranda da Silva, ambos vinculados ao grupo Teorias da Linguagem e Ensino (CNPq) e à linha Lingua(gem) em contexto de ensino de português (LM). Projeto aprovado pelo Comitê de Ética, cadastrado na Plataforma Brasil, pelo CAE 94344318.6.0000.5182. 
o gênero em análise. Além deste, outros autores, como Bakhtin ([1979] 1997) e Miller (2012), nortearam a discussão em torno do tema, estrutura composicional e papéis sociais dos sujeitos que fomentam a existência dos gêneros em foco.

\section{A NOÇÃO DE GÊNERO SOB A PERSPECTIVA SOCIODISCURSIVA E SOCIORRETÓRICA}

Há alguns séculos percebe-se uma preocupação em compreender e organizar textos segundo as especificidades de cada tipo e características comuns entre diversos, bem como aspectos distintivos, o que caracterizou, inicialmente, o estudo dos gêneros. Porém, o destaque para o caráter social da linguagem que configura os gêneros ganhou maior importância com as análises dos enunciados realizadas por Mikhail Bakhtin, cujas considerações se tornaram um marco da Linguística Moderna.

Em seu ensaio "Os gêneros do discurso", Bakhtin ([1979] 1997) afirma que os estudos anteriores pautados nas dimensões artístico-literárias, nas distinções intergenéricas dos gêneros literários e as análises estruturalistas dos gêneros do cotidiano realizados pelos estudiosos da retórica na Antiguidade se configuravam como um abstracionismo infértil (1997 [1979], p.280-281). Na compreensão do autor, se faz necessário considerar a diversidade e a heterogeneidade 
do discurso que compõem os gêneros e se efetua por meio dos enunciados orais e escritos. Esses quando observados isoladamente podem refletir a individualidade, porém os tipos relativamente estáveis de enunciados são elaborados por cada esfera de utilização da língua, é o que define gêneros do discurso (1997 [1979], p.279). Dessa forma, os modos variados de usos linguísticos possuem uma relação inviolável com a variedade da atividade humana, esse vínculo representa que:

A riqueza e a variedade dos gêneros do discurso são infinitas, pois a variedade virtual da atividade humana é inesgotável, e cada esfera dessa atividade comporta um repertório de gêneros do discurso que vai diferenciando-se e ampliando-se à medida que a própria esfera se desenvolve e fica mais complexa. (BAKHTIN, 1997 [1979], p.279)

Outra reflexão bakhtiniana que norteou grande parte dos estudos acerca dos gêneros textuais se constitui dos elementos que caracterizam os enunciados: conteúdo temático, estilo e construção composicional. O primeiro trata-se dos temas que constroem e circulam no enunciado, o segundo é composto pelas características do enunciado que podem ser associadas à identidade do locutor e do seu grupo social e o terceiro corresponde à organização linguística do enunciado e do gênero. Esses três elementos 
fundem-se indissoluvelmente no todo e são marcados pela especificidade de uma esfera de comunicação ligada à atividade humana que são todos os eventos nos quais o homem participa e estão relacionadas ao uso da língua.

Possamai e Leipnitz (2007) comparam as concepções sociodiscursivas de Bakhtin, no tocante ao conceito de "esferas de atividades", com as considerações sociorretóricas de Jonh M. Swales, com relação ao que denomina de "comunidades discursivas". As autoras afirmam que ambas as expressões se aproximam no sentido de reconhecer os gêneros como fruto dos usos da linguagem em situações sociais de comunicação, porém:

As comunidades discursivas, de Swales, são mais restritas, tanto que ele exclui de seu foco duas áreas da atividade verbal: a conversa casual e a narrativa simples, considerando-as pré-gêneros. Contrapondo as ideias de Bakhtin e de Swales, percebemos que se distanciam nesse ponto, pois, para Bakhtin, toda utilização da língua efetua-se em forma de enunciados, e cada esfera de utilização desses enunciados elabora tipos relativamente estáveis dele. (POSSAMAI E LEIPNITZ, 2007, p.2020-2021)

Isto é, para Swales, as afinidades de propósitos comunicativos na atividade verbal é o que forneceriam as bases para a constituição de um gênero. No entanto, para 
Bakhtin, "o critério de agrupamento é a própria atividade discursiva, os propósitos comunicativos parecem estar implícitos na ideia de pertinência de um enunciado a um gênero" (POSSAMAl; LEIPNITZ, 2007, p.2021).

Swales, preocupado com as questões relacionadas ao ensino do inglês, estabeleceu teorias e metodologias que têm sustentado pesquisas voltadas para análises de gêneros textuais, especialmente por oferecer conceitos-chave para o reconhecimento dos gêneros textuais e das práticas sociais que os envolvem, numa perspectiva sociorretórica. O seu estudo subsidiou a criação do modelo CARS (Create $a$ research space) que contribuiu para grande parte dos estudos voltados às descrições de diversas formas textuais, pois esse padrão de análise de gêneros textuais, que se caracteriza pela regularidade dos movimentos retóricos, possui força e flexibilidade suficientes para ser aplicado nos mais variados contextos (BIASI-RODRIGUES; HEMAIS; ARAÚJO, 2009, p.31).

Para compreender a construção desse modelo, ressaltemos alguns conceitos defendidos por Swales que emergem na sua definição de gênero como "uma classe de eventos comunicativos, cujos membros compartilham um conjunto de propósitos comunicativos" (SWALES, 1990, p.58, tradução nossa). Propósito comunicativo, para o autor, 
é um critério privilegiado que opera para manter o escopo de um gênero estritamente focado em uma ação retórica comparável.

Além do propósito, afirma que exemplares de um gênero exibem vários padrões de similaridade em termos de estrutura, estilo, conteúdo e público-alvo. E se todas as altas probabilidades de expectativas forem realizadas, o exemplar será visto como prototípico pela comunidade discursiva de origem. Os nomes dos gêneros herdados e produzidos por comunidades discursivas e importados por outras constituem uma comunidade etnográfica valiosa, mas tipicamente precisam de uma avaliação posterior.

Essas definições revelam que o autor focaliza os eventos comunicativos como a base para a constituição de um gênero e para a identificação da sua estrutura, estilo e conteúdo, considerando também o público-alvo. Reconhecer um gênero textual se torna, assim, fruto de um processo de percepção das ações retóricas de uma comunidade discursiva que institui seus padrões a partir de propósitos comunicativos comuns.

Dessa forma, o autor propõe uma análise descritiva de gêneros que foca nas ações retóricas encontradas recorrentemente em exemplares de uma classe de eventos 
comunicativos com propósitos compartilhados por seus membros. As ações organizam as informações do texto por meio de movimentos retóricos, isto é, através de unidades de estrutura discursivas com características e funções específicas. Essa é a base para o modelo CARS.

O método começou a ser elaborado por Swales a partir da observação de 48 introduções de artigos de pesquisa e, em um segundo momento, estendeu para 110 em áreas diferentes nas quais notou uma regularidade de quatro movimentos (moves) que representam a composição textual desses objetos (BIASIRODRIGUES; HEMAIS; ARAÚJO, 2009, p.29).

Os movimentos se tratam da modelização da escrita do texto que são fruto da sistematização das ações retóricas recorrentes e linguisticamente marcadas nos objetos analisados, cada uma delas com seus procedimentos descritos nos step (passos).

Assim, cada movimento retórico do modelo de Swales se caracteriza como uma unidade que representa a estrutura discursiva uniforme que expressa as características estruturais e funcionais específicas do gênero. A grande contribuição do método CARS para as pesquisas descritivas sobre gêneros está na apresentação de um modelo de observação sistemática que proporciona um ambiente de pesquisa. Em estudos posteriores o autor declara: 
O modelo CARS (create-a-research-space), de 1990, tem sido comparativamente bemsucedido, em termos tanto descritivos quanto pedagógicos (ou pelo menos é aquilo em que ingenuamente acredito), por ser relativamente simples e funcional, apoiado em corpora, sui generis para o gênero a que se aplica e por, pelo menos no estágio inicial, oferecer um esquema que até o momento não estava amplamente disponível. (SWALES, 2009, p.41)

Swales deixa claro que esta forma de sistematização, mesmo que eficiente para o levantamento de dados, serve a um estágio inicial de análise por refletir primariamente a realidade dos gêneros resultantes dos eventos comunicativos. Como o próprio autor afirma, qualquer estudo que objetive o reconhecimento de gêneros necessita de uma avaliação.

Nesse viés, Miller (2012), seguindo a abordagem retórica compartilha a consideração de que para que se realize uma definição de gênero retoricamente válida é necessário centrar-se não na substância ou na forma de discurso, mas na ação usada para sua realização. A autora também considera as situações retóricas recorrentes como forma de reconhecer a tipificação dos gêneros que é percebida por meio das características do contexto, das demandas situacionais identificadas pelos usuários e da motivação dos participantes do discurso, bem como os efeitos por eles pretendidos. 
A autora apresenta uma proposta para a avaliação das alegações genéricas, quando declara que a observação das características dos gêneros retóricos fornece orientações para as afirmações resultantes de descrições quanto às estruturas e aos funcionamentos. Para tanto, Miller (2012) evidencia a necessidade de considerar o significado e o contexto da situação em que as ações retóricas tipificam o discurso, afirma que o gênero é interpretável por meio de regras que são frutos de interações simbólicas, é distinto da forma, apresenta padrões recorrentes do uso linguístico que constituem a substância da nossa vida cultural e é o meio retórico para mediar as intenções privadas e a exigência social.

Em síntese, os estudos de Bakhtin, Swales e Miller se complementam por evidenciarem os aspectos discursivo, social e cultural para a análise de gêneros, bem como propõem métodos a serem considerados no reconhecimento e descrição das formas textuais que constantemente surgem ou transmutam nos diversos contextos de utilização da língua. Nesse sentido, no tópico a seguir nos baseamos nas noções aqui destacadas para apresentar o gênero videorresenha.

\section{METODOLOGIA}

A proposição de um modelo estrutural para o gênero ocorreu por meio da observação dos movimentos retóricos 
que são possíveis de serem destacadas nos textos híbridos publicados na rede social YouTube que exploram os recursos do suporte com o propósito e organização retórica e composicional semelhantes ao gênero resenha. Tal procedimento qualifica a nossa pesquisa como de natureza descritiva que assim pode ser definida por se enquadrar no que afirma Gil (1994):

As pesquisas deste tipo têm como objetivo primordial a descrição das características de determinada população ou fenômeno ou o estabelecimento de relações entre variáveis. São inúmeros os estudos que podem ser classificados sob este título e uma de suas características mais significativas está na utilização de técnicas padronizadas de coleta de dados. (p.28)

Portanto, podemos caracterizar a nossa análise como de cunho descritivo-interpretativista, por utilizar a técnica padronizada de coleta de dados que particulariza o caráter descritivo ao realizarmos uma observação sistemática da estrutura das videorresenhas selecionadas em canais do YouTube. Essa caracterização também se justifica pelo fato de lidar com os mundos naturais e sociais ao detalhar e analisar os recursos da mídia social como ferramenta para construção de conhecimento explanando e articulando as experiências da realidade social com os significados da pesquisa científica. 
Segundo Esteban (2010), a natureza interpretativista situa esta como uma pesquisa qualitativa definida pelo autor da seguinte forma:

\begin{abstract}
A pesquisa qualitativa é uma atividade sistemática orientada à compreensão em profundidade dos fenômenos educativos e sociais, à transformação de prática e cenários socioeducativos, à tomada de decisões e também ao descobrimento de um corpo organizado de conhecimentos. [...] Uma característica fundamental dos estudos qualitativos é sua atenção ao contexto [...]. (2010, p.127-129)
\end{abstract}

Assim, o tratamento dos dados é de natureza qualitativa por buscar compreender as características do cenário da tecnologia como ferramenta disponível para a ocorrência de novos gêneros textuais e de inspiração netnográfica, devido à inserção do pesquisador na comunicação mediada por computador para observação do objeto de análise (AMARAL; NATAL; VIANA, 2008).

Como amostragem para as alegações aqui apresentadas, analisamos três videorresenhas (VR) identificadas a seguir:

- VR1: "Bem Amado (Dias Gomes) UNICAMP"3 - Canal "Tatianagfeltrin" (Playlist: "Livros de vestibular");

- VR2: “Memórias Póstumas de Brás Cubas, Machado

3 In https://www.youtube.com/watch?v=p0CrqUdimjU\&t=191s, com duração de 07'38". Acesso em 20.Set.2018. 
de Assis (\#24)"4 - Canal "Ler antes de Morrer" (Playlist: "Literatura nos vestibulares");

- VR3: "Sagarana - Guimarães Rosa - FUVEST"5 - Canal "Vá ler um livro" (Playlist: "Resenhas - Lista obrigatória (vestibulares)".

Como forma de facilitar a identificação dos momentos de execução dos movimentos retóricos a serem analisados no tópico a seguir, organizamos o Quadro 1 no qual são expostos os recortes temporais nos quais os movimentos são reconhecidos e quando há sua ausência:

4 In https://www.youtube.com/watch?v=cbYjiH7-2jk\&index $=25 \& \mathrm{t}=6 \mathrm{~s} \&$ list= PLGXaCx6vCa9txBI6iw7g2Y038fbM9PvJX, com duração de 09'59”. Acesso em 20.Set.2018.

5 In https://www.youtube.com/watch?v=M1r1hZUQ2AI\&list=PLL8CLxt4Mr C9ILXX0b8C_OZdCfKdcohm\&index=17), duração com de 09'39”. Acesso em 20.Set.2018. 


\begin{tabular}{|c|c|c|c|c|c|c|}
\hline & \multicolumn{3}{|c|}{ DESCRIÇÃO } & \multicolumn{2}{|c|}{ ARGUMENTAÇÃO } & \multirow{2}{*}{$\begin{array}{c}\text { EXPOSIÇÃO } \\
\text { Informações } \\
\text { adicionais }\end{array}$} \\
\hline & Contextualização & $\begin{array}{c}\text { Apresentação } \\
\text { das partes }\end{array}$ & $\begin{array}{c}\text { Descrição } \\
\text { global }\end{array}$ & Avaliação & Recomendação & \\
\hline \multirow{5}{*}{$\begin{array}{c}\text { VR1 } \\
\text { (07'38”) }\end{array}$} & $00 ' 16 "-01 ' 45 "$ & & & & & \\
\hline & & $01^{\prime} 46^{\prime \prime}-05^{\prime} 27^{\prime \prime}$ & & & & \\
\hline & & & $05^{\prime} 28^{\prime \prime}-06^{\prime} 44^{\prime \prime}$ & & & \\
\hline & & & & $06 ' 45^{\prime \prime}-07 ' 15^{\prime \prime}$ & $06{ }^{\prime} 45 "-07 ' 15 "$ & \\
\hline & & & & & & 07'16"- 07'38' \\
\hline \multirow{8}{*}{$\begin{array}{c}\text { VR2 } \\
\text { (09'59”) }\end{array}$} & $00^{\prime} 00^{\prime \prime}-04^{\prime} 27^{\prime \prime}$ & & & & & \multirow{8}{*}{$\mathrm{X}$} \\
\hline & & & $04 ' 28$ '- 06'14"' & & & \\
\hline & & & & $05 ’ 25 "-06 ’ 14 "$ & & \\
\hline & & $05^{\prime} 54^{\prime \prime}-06^{\prime} 04^{\prime \prime}$ & & & & \\
\hline & $06 ' 15 "-07 ' 33 "$ & & & & & \\
\hline & & & $07^{\prime} 34^{\prime \prime}-08^{\prime} 29^{\prime \prime}$ & & & \\
\hline & & & & $08^{\prime} 29^{\prime \prime}-09 ' 31 "$ & & \\
\hline & & & & & 09’32”- 09'59”' & \\
\hline \multirow{5}{*}{$\begin{array}{c}\text { VR3 } \\
\text { (09'39”) }\end{array}$} & $00 ’ 00 ”-01 ' 46 "$ & \multirow{5}{*}{$\mathrm{X}$} & & & & \\
\hline & & & $01 ' 47 ”-08 ’ 33 "$ & & & \\
\hline & & & & $08 ’ 34 ”-08 ' 50 "$ & & \\
\hline & & & & & 08'51"'-09'01”' & \\
\hline & & & & & & 09'02"- 09'39"' \\
\hline
\end{tabular}

Quadro 1 - Recortes temporais dos movimentos retóricos. Fonte: Elaboração da própria autora. (2018)

A representação do quadro acima se baseia em recortes temporais aproximados e categorizados a partir dos períodos em que os movimentos retóricos elencados são mais destacáveis, pois por se tratar de um texto oral em um evento comunicativo com menor rigor formal, a organização dessas etapas não é estanque, mas em diversos momentos a apresentação do enredo e a avaliação da obra ocorrem simultaneamente, bem como as descrições e a recomendação, as informações adicionais e a contextualização, etc. 


\section{O PROTÓTIPO PARA O GÊNERO VIDEORRESENHA}

Em uma observação panorâmica de setenta e sete videorresenhas, postadas em playlists dos três canais identificados, devido às repetições de estruturas e de funcionamento, pudemos selecionar três exemplares, como amostragem deste universo. Constata-se a ocorrência de movimentos retóricos semelhantes à resenha, através da execução de sequências textuais de descrição e argumentação.

Além disso, a realização do texto na modalidade oral, o contexto da situação comunicativa e o suporte de publicação remodelam a maneira como as sequências acontecem em comparação ao gênero tradicional, resenha, inspirador à existência e funcionamento da videorresenha. Tal fato evidencia a interdependência entre a dinamicidade nas escolhas linguísticas e do estilo como fatores intervenientes para a diversificação dos produtos.

Um exemplo que ilustra essa dinamicidade pode ser mencionada em relação à execução dos movimentos retóricos de contextualização e apresentação das partes que pertencem marjoritariamente à sequência descritiva, de descrição global que, nas videorresenhas, oscila entre as sequências descritivas e argumentativas, bem como 
de avaliação e recomendação que se dispõe por meio de sequências argumentativas. Essa característica do objeto em análise, já destacada por Marcuschi (2006) ao afirmar que os gêneros são entidades dinâmicas, se torna ainda mais evidenciada devido ao ambiente em que circula.

Outro aspecto que tipifica um modelo para o gênero videorresenha, delineado pelas particularidades do suporte, se trata do surgimento de um movimento retórico que comumente não acontece no gênero primário, aqui denominamos de informações adicionais, cujos exemplos serão apresentados adiante.

As informações adicionais são produto do caráter dos canais que abrigam as videorresenhas analisadas em manter uma recorrência de publicações semanais e de criarem uma série de vídeos em que se dão continuidade uns aos outros. Elas ocorrem então por meio de sequências expositivas nas quais são apresentados informes sobre fatos e situações que não remetem propriamente à análise da obra resenhada, mas a outros conteúdos relacionados ao canal, ao produtor ou a outros vídeos e sites.

Nesse sentido, baseando-se em Swales (1990), podemos estabelecer uma representação esquemática que se propõe a captar a organização retórica que comumente encontra-se nas ocorrências do gênero videorresenha: 


\section{SEQUÊNCIA DESCRITIVA}

\section{MOVIMENTO 1 - Contextualizar a obra}

Passo 1 - Situar características da escola literária e/ou

Passo 2 - Informar dados que caracterizam o ambiente de produção/publicação da obra e/ou

Passo 3 - Apresentar informações sobre o autor e/ou

Passo 4 - Realizar ilustrações que direcionem a compreensão das informações gerais

\section{MOVIMENTO 2 - Apresentar as partes}

Passo 1 - Sumariar o conteúdo e/ou

Passo 2 - Descrever a organização estrutural do conteúdo na obra e/ou

Passo 3 - Apresentar a estruturação da edição selecionada

\section{MOVIMENTO 3 - Realizar descrição global}

Passo 1 - Explicar alegações sobre as partes do conteúdo da obra e/ou

Passo 2 - Promover relações intertextuais e/ou

Passo 3 - Caracterizar personagens, ambientes e ações e/ou

Passo 4 - Ler fragmentos textuais e explicitar a relação das descrições com a leitura do fragmento

\section{SEQUÊNCIA ARGUMENTATIVA}

\section{MOVIMENTO 4 - Avaliar a obra}

Passo 1a - Julgar o conteúdo de forma global ou

Passo 1b - Qualificar o conteúdo de cada tópico levantado sobre o conteúdo

\section{MOVIMENTO 5 - Recomendar a leitura}

Passo 1a - Incentivar o acesso à obra ou

Passo $1 \mathrm{~b}$ - Desestímulo ao acesso à obra e/ou

Passo 2 - Sugerir formas de melhor aproveitamento da leitura

\section{SEQUENCIA EXPOSITIVA}

\section{MOVIMENTO 6 - Adicionar informações}

Passo 1 - Citar informações extratextuais e/ou

Passo 2 - Informar sobre links de acesso a conteúdos complementares e/ou

Passo 3 - Comunicar o funcionamento do canal/playlist e/ou

Passo 4 - Requisitar atitudes para a contribuição com o crescimento do canal

Quadro 2 - Representação esquemática do protótipo para o gênero videorresenha. Fonte:

Elaboração da própria autora. (2018) 
Na organização do quadro consideramos os movimentos retóricos pertinentes a cada sequência tipológica textual, bem como as possíveis estratégias (passos) utilizadas para a execução das partes do texto. O esquema resulta dos aspectos elencados pela descrição das videorresenhas considerando que não obrigatoriamente seguem a ordem apresentada, conforme comprovação dos movimentos retóricos que serão apresentados no subtópico que segue.

3.1. A execução dos movimentos retóricos nas videorresenhas

O primeiro movimento retórico, bem como os demais movimentos pertencentes à sequência descritiva, é o momento em que se nota a maior aproximação ao gênero resenha. Assim, os objetivos em realizar uma contextualização se tratam da descrição de informações externas ao conteúdo da obra resenhada. No entanto, a disponibilidade do suporte em possibilitar a exploração dos recursos multimodais integrados à fala e as exigências de atrair a atenção do espectador permitem a utilização de ilustrações que direcionam a compreensão das informações gerais.

Tal estratégia utilizada no momento de contextualizar, que comumente não acontece em resenhas tradicionais, modela uma característica particular ao gênero videorresenha. Vejamos como retoricamente ocorrem essas estratégias: 


\section{VR2 - Movimento retórico de contextualizacão}

\section{TRECHO 1}

eu acho que é um pouco por causa disso que antigamente era muito comum que as pessoas escrevesse em:: cadernos diá::rios contando como eram suas vidas o seu dia a dia talvez fosse uma forma de elas dizerem pro mundo que EI eu existi:: olha aqui:: eu tive uma vida uma forma de vencer a mortalidade... e era tão comum esse gênero livros de memórias... que certa vez um escritor brasileiro... de um certo talento resolveu se basear em um livro de memórias pra escrever um romance e o resultado... revolucionou a literatura brasileira (00'37" - 01'12")

A contextualização representada no trecho 1 , que revela estratégias bastante recorrentes nas videorresenhas dessa produtora, não ocorre pela citação de características que situam um dado momento histórico-literário como ponto de partida para início da apreciação da obra, fato que ocorre em grande parte das demais videorresenhas. No entanto, são apresentadas ilustrações que permitem compreender o contexto, que na fala podem ser demonstradas por meio de expressões como "talvez fosse uma forma de elas dizerem pro mundo que El eu existi:: olha aqui:: eu tive uma vida". A expressão surge de um momento de descrição de uma cena arquitetada para que o interlocutor pudesse visualizar o cenário que proporcionou o surgimento da obra e estabelecer, assim, suas interpretações.

Outra característica das videorresenhas divulgadas nessa playlist está relacionada ao fato de que são poucas as 
ocorrências de momentos em que a apresentação das partes fique evidente como o principal objetivo dos movimentos retóricos. Isso revela a sua maior preocupação em estabelecer intertextualidades e intepretações do que a exposição das partes do enredo. Vejamos como se constituem os movimentos retóricos quando há a apresentação das partes:

\section{VR2 - Movimento retórico de apresentacão das partes/avaliacão}

\section{TRECHO 2}

e é desse jeito com muita franqueza com muita sinceridade com muito sarcasmo que ele vai contar como foi a sua vida a infância a juventude a velhice e a morte e vai contar sobre as coisas que ele f::ez as pessoas que ele conheceu as coisas que ele DEIxou de fazer e por aí vai (05'48" - 06'03")

Nesse mesmo fragmento há um relato de fatos do enredo que delineiam uma ação retórica que caracteriza esse movimento. Porém, encontramos marcas linguísticas que remetem a uma avaliação quanto à linguagem utilizada pelo autor da obra nas falas do personagem principal, são elas "com muita franqueza", "com muita sinceridade" e "com muito sarcasmo". Isso demarca a característica do gênero no contexto em que está inserido de permitir a simultaneidade de movimentos retóricos.

Já descrição global pertence à sequência descritiva que, comumente, sucede ou se intercala ao momento de 
apresentação das partes. Com maior recorrência e maiores durações, os produtoresutilizamcomoestratégias, explicações e intertextualidades que promovem a compreensão dos aspectos relacionados ao enredo, caracteriza personagens, ambientes e ações, e explicita a relação das descrições com a leitura do fragmento, observemos alguns exemplos nos trechos que seguem:

\section{VR3 - Movimento retórico de descrição global}

\section{TRECHO 3}

uma dos/uma das novelas na verdade se chama a volta do marido pródigo e na bíblia a gente tem uma histó::ria caso você não conheça que se chama a volta do filho pródigo que é o filho de um cara que acaba desaparecen::do e gastando vários dinhe::iros e tal e ai ele volta depois e tem todo uma lição de perdãa::o e aceitação e é ai aqui a gente tem um verão que é um marido pródigo que acaba sumindo e tal e ele volta pra tentar reconquistar a mulher só que ela já tá apaixonada por outro assim então essa é a parte da universalidade né (05'15" - 05'45”)

No trecho 3, ao mencionar outra narrativa que remete à parte do enredo da obra resenhada, o produtor usa como estratégia a discussão sobre a intertextualidade como uma forma de evidenciar suas características e proporcionar a compreensão do conteúdo.

Ainda com relação à sequência argumentativa, podemos comprovar a presença de características que aproximam as 
videorresenhas ao gênero resenha por meio da realização do movimento retórico de recomendação. Apesar de ser executado em momentos mais breves durante todas as produções em que ocorre, a sua recorrente presença na maioria das videorresenha apresentadas no três canais o constituem como parte integrante da estrutura do gênero, assim como da resenha tradicional. Observemos o trecho a seguir:

\section{VR2 - Movimento retórico de recomendação}

\section{TRECHO 04}

e se você está estudando Memórias Póstumas de Brás Cubas PAra o vestibular aproveite essa oportunidade para conhecer um dos livros MAis bonitos já escrito na Língua Portuguesa ... (09'32" - 09'44')

Tendo em vista o objetivo da playlist de tratar conteúdos literários exigidos por exames de ingresso em universidades, a recomendação destaca a presença do romance na lista de leituras obrigatória para um vestibular específico, por isso a necessidade em estudá-la. Também deixa subentendido que não só os estudantes devem ter acesso a essa obra, mas também o público em geral, uma vez que as marcas de avaliação evidenciam o seu valor literário para a produtora.

A maioria das videorresenhas das playlists, e este já é um costume consolidado em todas as variações de 
vídeos que são fruto do fenômeno vlog (diário em vídeo), o encerramento ocorre por meio da remissão a outras informações que podem ser acessadas por meio de links e hiperlinks e/ou o anúncio das próximas publicações. Esses momentos fogem à contemplação da obra, apresentando em si uma característica particular da videorresenha no suporte e em um canal com objetivos de realizar a análise de uma sequência de livros. A essas estratégias denominamos de informações adicionais. Vejamos como elas ocorrem nos trechos a seguir:

\section{VR1 - Movimento retórico de informações adicionais}

\section{TRECHO 05}

então antes de encerrar vamos combinar nosso próximo encontro para as leituras de vestibular... no dia vinte e cinco de agosto nos encontramos então pra conversar sobre o "Espelho" de Machado de Assis (07'16" - 07'25")

O trecho 5 representa o momento em que a produtora expõe os horários das novas publicações a serem acessados nas datas mencionadas, temos nesse momento o predomínio de uma sequência textual expositiva. No entanto, o que mais caracteriza a linguagem do suporte nesse movimento está na expressão "dar um joinha ajudar a compartilhar", pois essas ações requeridas são unicamente realizadas no 
suporte do YouTube e ambas indicam o clique em hiperlinks pertencentes à estruturação da mídia social os quais medem a popularidade do vídeo.

\section{CONSIDERAÇÕES FINAIS}

A crescente imersão no contexto tecnológico é uma das características mais marcantes da nossa sociedade contemporânea. As redes sociais já se tornaram parte integrante do nosso cotidiano e meio para comunicação nas mais diversas situações, quer seja para envio de recados através de aplicativos de mensagens instantâneas, quer seja para publicação de textos em vídeos com intuito de divulgar conteúdos para um grande público, por exemplo.

Tal fato resulta na ampla circulação de diversos textos no ambiente digital, muitos deles transpostos do formato impresso para o contexto virtual que migraram dos moldes clássicos para novas estruturas repletas de formas de interatividade. Assim, percebe-se a proliferação de uma variedadade de textos cada vez mais híbridos em suas semioses, fruto das possibilidades de associar diferentes modalidades textuais e recursos provenientes do meio digital. Tal fato proporciona aos gêneros já consolidados novas estruturas e funções resultando na origem de novos gêneros. 
Nesse sentido, compreender a estrutura, o funcionamento e os aspectos que circundam o gênero videorresenha propicia aos professores de língua portuguesa um instrumento complementar às suas práticas docentes que traz muitos ganhos no desenvolvimento de reflexões sobre as práticas linguísticas por parte dos alunos.

Primeiro, porque proporciona atividades mais atrativas que colaboram com a aquisição de conhecimento a respeito de outros gêneros, como a resenha, por exemplo. Segundo por possibilitar a expansão das capacidades críticas, descritivas, expositivas e interpretativas dos educandos. E acima de tudo utilizar instrumentos como esse caracterizam práticas docentes que demonstram compreender que estudar a língua vai muito além do ato de decorar regras e estrutura, mas é lançar um olhar sobre o nosso próprio cotidiano.

\section{REFERÊNCIAS}

AMARAL, Adriana; NATAL, Geórgia; VIANA, Luciana (2008). "Netnografia como aporte metodológico da pesquisa em comunicação digital". Cadernos da escola de comunicação, 1(6), 1-12.

BAKHTIN, Mikhail ([1979] 1997). "Os gêneros do discurso". In: BAKHTIN, Mikhail. Estética da Criação Verbal. São Paulo: Martins Fontes.

BIASI-RODRIGUES, Bernardete; ARAÚJO, Júlio César; SOUSA, Socorro Cláudia Tavares de (Orgs.) (2009). Gêneros textuais e comunidades discursivas: um diálogo com John Swales. Belo Horizonte: Autêntica.

ESTEBAN, Maria Paz Sandín (2010). Pesquisa qualitativa em educação: fundamentos e tradições. Porto alegre: $\mathrm{AMGH}$. 
GIL, Antonio Carlos (1994). Administração de recursos humanos: um enfoque profissional. Editora Atlas.

MARCUSCHI, Luiz Antônio, et al. (2006). Gêneros textuais: reflexões e ensino. Rio de Janeiro: Lucerna.

MILLER, Carolyn Rae (2012). "Gênero como ação social". In: DIONISIO, Angela Paiva; HOFFNAGEL, Judith Chambliss (Orgs.). Gênero textual, agência e tecnologia. São Paulo: Parábola Editorial.

POSSAMAI, Viviane; LEIPNITZ, Luciane. (2007). “Os estudos de gênero e a tradução: uma relação proveitosa demonstrada por meio da abordagem da tradução de artigos científicos". Anais do IV SIGET.

SWALES, John (1990). Genre analysis: english in academic and research settings. Cambridge University Press.

(2009). "Repensando gêneros: uma nova abordagem ao conceito de comunidade discursiva". In: BIASI-RODRIGUES, Bernardete; ARAÚJO, Júlio César; SOUSA, Socorro Cláudia Tavares de (Orgs.) Gêneros $e$ sequências textuais. Belo Horizonte: Autêntica.

Flávia Thaís Alves Britto é mestranda pelo Programa de Pós-graduação em Linguagem e Ensino da Universidade Federal de Campina Grande (UFCG), integrante do grupo de pesquisa Configurações de Ensino em Práticas Multidisciplinares de Linguagem(ns).

E-mail: flavia_britto_@hotmail.com

Williany Miranda da Silva é pós-Doutora pala Universidade Federal de Minas Gerais (UFMG) (2013), Mestre e Doutora em Letras pela Universidade Federal de Pernambuco (UFPE). É professora associada da graduação e membro do Programa de Pós-graduação em Linguagem e Ensino da UFCG. Integrante do grupo de pesquisa Configurações de Ensino em Práticas Multidisciplinares de Linguagem(ns).

E-mail: wiliany.miranda@gmail.com 